Back From The Brink: Successes in Wildlife Conservation, by Guy Mountfort. Hutchinson, $£ 5.50$

This is a timely and a cheering book, popularly written, too, which in this case means easily read, and well illustrated. So much of the conservation story is depressing. The negative factors are so often linked to inevitably advancing destructive processes arising from the proliferation of our own species that it must often seem to conservationists that they are in a losing game from the start. Therefore Mr Mountfort has put together a number of success stories. Sometimes these deal with particular animals-Arabian oryx, barasingha, vicuña, orang-utan, giant flightless grebe, nene, Asian lion, rhinoceros and tigers; sometimes with a particular place- Dudhwa National Park, Galapagos Islands, Aldabra, the Seychelles (especially Cousin Island); sometimes with special people-Peter Scott (who writes a foreword to the book), Ian Grimwood, Arjan Singh, Ann Labastille, Felipe Benavides - who have contributed a special motive force. An excellent idea. And in all the instances chosen the author himself has either played a part or at least been on the spot. He can describe the scene as seen with his own eyes, he knows the mammals and the birds, and he also knows the people who were, in a double sense of the words, principally concerned. This gives an immediacy and a conviction to his tales.

The author does not minimise the changes and has a final chapter: The Task Ahead. Yet I could have wished that, without in any way encouraging despair, he also emphasised the precariousness of every victory won. Using but little imagination, the reader can easily understand how quickly events such as a change of government in one case, a change of policy induced by commercial pressures in another, or just the termination of positive pressure by the ultimate disappearance of a particular individual enthusiast in yet another, could reverse all that has been gained, especially where the species rescued have been limited to one area. The price of conservation, like that of liberty requires eternal vigilance.

IVOR MONTAGU

\title{
Wildlife in Britain and Ireland, by Richard Perry. Croom Helm, $\mathfrak{f}^{7.25}$.
}

Starting with the broad generalisation, "Animals become extinct or decrease in numbers mainly because of the destruction of their habitat, or because they are unable to adapt to changes in this...' (the first sentence of the book), the author provides a fascinating and valuable survey of Britain's animal life from prehistoric times to the present day. He points out that man was making his 'first slight impact' on wildlife as early as the Old Stone Age, but it was not until about 100 or $75 \mathrm{BC}$ that he began to make the first major impact with the agricultural activities of the Belgae, entailing extensive destruction of the forests, later to be intensified by the Saxons. It is unlikely, however, that extermination of the larger carnivores in Britain was delayed because they had to confine their clearing operations to the lighter forest, owing to the danger of malaria or ague in the 'waterlogged jungles on the heavy clay land'; the vector of the malaria parasite in this country, Anopheles maculipennis atroparvus, is mainly a coastal species.

With the help of a quite remarkable and extensive collection of quotations and references from early writings, the author gives interesting details of the status and fate through the centuries of most of our native fauna, from elks to insects, but with special emphasis on birds. Particularly interesting, if disturbing, is the well-researched account of the decline in birds of prey after the seventeenth century when, with the waning popularity of falconry, the protection previously given to falcons and hawks was relaxed, and the decline was accelerated by the enclosures, sheep farming and the preservation of the sportsman's game, which entailed the virtual extinction of all potential predators.

On a happier note the author describes the new habitats that 'came into existence during the latter half of the 18th century with the introduction to the landscape of plantations and gardens around gentlemen's houses'. More recently we have seen the return of species such as nesting redwings, fieldfares, firecrests and Cetti's warblers as 